\title{
Interjective 'what'*
}

\author{
Jesse A. Harris \\ Pomona College
}

\begin{abstract}
Discourse particles and interjectives allow a speaker to signal how information presented in an utterance relates to her epistemic or emotive state. I present a semantics for one such interjective: the English particle what. In addition, I provide evidence that it carries multiple discourse functions, and propose that these distinct uses are best captured by their relation to the central discourse topic.
\end{abstract}

Keywords: Discourse particles; questions; approximation; prosody; corpus pragmatics.

\section{Introduction}

In a cooperative talk exchange, speakers do more than simply try to impose their beliefs on other members of the discourse in short, declarative sentences. For example, speakers may indicate how they came to know the information they wish to communicate, and how strongly they are committed to it. Many languages use discourse particles for just this purpose (Zimmermann 2011). Although English is thought not to use discourse particles proper, it does possess similar items conveying rich Speaker commitments, for example, the colloquial particle man (McCready 2008). In this paper, I consider the case of intrasentential what as in (1), a ubiquitous, yet understudied interjective (though see Clark 2004 and Dehé \& Kavalova 2006).

(1) There were what, 60 people at SALT this year?

I propose that, appearances aside, utterances with intrasentential what are best treated not as syntactic $w h$-in-situ questions, but rather as involving hesitation markers conveying that the Speaker's presumed (or public) epistemic state is weakened. Specifically, the what marker is treated as a focus sensitive operator which delivers a set of propositions. The result is semantically equivalent to a Hamblin-style denotation for questions (Hamblin 1973; Kratzer \& Shimoyama 2002), restricted

* Many thanks to Ana Aguilar, Noah Constant, Donka Farkas, Lyn Frazier, Meredith Landman, Angelika Kratzer, Chris Potts, Jessica Rett, Lisa Selkirk, Radek Šimík, and Matthijs Westera for discussion, and to the participants both at CUSP 5 and SALT 23 for their feedback and examples. Special thanks to Jay Atlas for a close, critical reading of the penultimate draft. Any errors or misrepresentations are mine alone.

(C)2013 Harris 
to a contextually salient domain of possible answers. As proof of concept, I offer a compositional meaning developed within the Alternative Semantics framework (Rooth 1985; Kratzer 1991).

In addition to queries, intrasentential what may also evince approximative or bestguess uses, which I call weak assertion cases, in which no direct answer response is typically anticipated. I propose that any use of interjective what pragmatically raises issues for the discourse by virtue of its question-like semantics. However, depending on how the issue relates to the immediate discourse topic, it can be resolved through a direct answer or left as an open issue. Predictions of the approach are evaluated against evidence obtained from a fragment of the Switchboard corpus (Godfrey, Holliman \& McDaniel 1992). Thus, one and same meaning of what is sufficient for two different uses, which can be distinguished - and treated - on the basis of independent discourse factors.

The remainder of the paper is organized as follows. After presenting the main descriptive properties of examples like (1), I consider three plausible analyses of intrasentential what, arguing in favor of an account which takes what to provide multiple discourse functions. In section 4, I show how such a meaning can be derived compositionally. Section 5 addresses how discourse-level nuances determine whether what is interpreted as an approximation or as a question, with corpus evidence offered in support of the main claims. Section 6 concludes.

\section{The distribution of intrasentential what}

Intrasentential what commonly appears in conversational and informal speech settings. Orthographically, it is most common to find what written with commas like an appositive, as illustrated in (2b-c), although other forms are occasionally attested, as in $(2 \mathrm{a}, \mathrm{d})$.

(2) a. There's been what? A dozen and a half murders since I've been here.

(Hammett 1929: Red Harvest)

b. I recognize you though it's been, what, 30 years?

(Midsomer Murders: Season 2)

c. You think that what, twenty deserters from the Sudanese army are going to come back and make Sudan a Communist nation?

(Eggers 2006: What is the what)

d. Woody's what? 73? he'll be writing this stuff 'til he's what? 95? so we might as well get comfortable ...

(http://popwatch.ew.com/popwatch/2009/05/whatever-works.html)

In what follows, I will ignore sarcastic and aggressive uses of what which often appear preceded by so in sentence initial position (Dehé \& Kavalova 2006). Whether 
Interjective what

such uses are related to the cases of interest will remain an open question. As such, I will reserve what to demarcate the cases at hand and use what for other, string identical cases:

(3) So, what, my father was Dr. Mengele?

(Heroes: Season 3)

Finally, I will refer to the constituent following what as the complement of what, without committing to any particular syntactic analysis of the expression. The clause modulo what will be referred to as the prejacent.

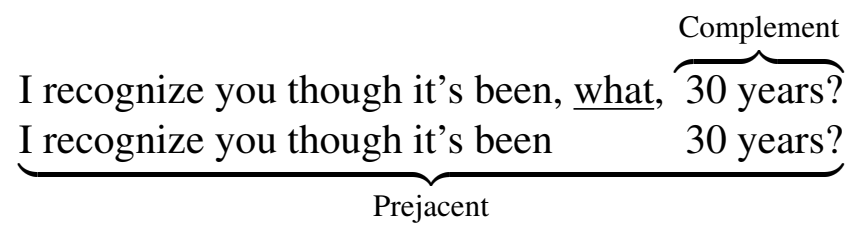

In the next section, I briefly discuss the syntactic distribution of what with respect to its complement.

\subsection{Syntactic licensing}

As observed by Dehé \& Kavalova (2006), the what-marker is relatively unconstrained in terms of its syntactic distribution, appearing with DP, PP, and VP complements. By and large, there is a general preference to place what to the immediate left of the element it modifies.
a. You've already acted in, what, two plays this year?
(DP complement)
b. You've already acted, what, in two plays this year?
(PP complement)
c. You've already, what acted in two plays this year?
(VP complement)

Dehé \& Kavalova (2006) conducted a corpus study of what in British English and observed that the vast majority of examples involved a complement with a numerical phrase. Accordingly, Dehé \& Kavalova (2006) propose that what is syntactically a short parenthetical, structurally independent of its host, and licensed by an abstract NUM feature on the XP it dominates. ${ }^{1}$

However, in American English, at least, counterexamples to the numerical restriction can be readily found:

(6) It's filled with what, whip cream ... and strawberries and something

(Switchboard)

1 Dehé \& Kavalova's (2006) account is actually a great deal more complicated, as the linearization of what relative to elements within the phrase to which it merges is determined by optimizing Relevance Theoretic demands. In the interest of brevity, I will not spell out their proposal in any detail here. 
(7) I haven't seen you since, what, Lebanon? Bosnia? (Burn Notice: Season 3)

To determine how common such non-numerical cases are, I conducted a pilot corpus study on the fragment of the Switchboard corpus (Godfrey et al. 1992) included in the Natural Language ToolKit (Bird, Klein \& Loper 2009). From the first 2,000 cases of string-identical what, 18 instances of intrasentential what were observed. Of those, $40 \%$ preceded non-numerical complements, suggesting that they are considerably more common than would be expected from Dehé \& Kavalova's (2006) account.

One advantage of the account below is that it permits us to explain why what appears most often with numerical complements, all while allowing non-numerical cases, whose licensing follows naturally from independently plausible semantic and pragmatic considerations. In the following section, I briefly introduce the main prosodic patterns that appear in utterances with what.

\subsection{Prosodic realization}

The what element presents a unique prosodic pattern. It is produced with a low (L\%) as in (8) or low-fall (H- L\%) as in (9) boundary tone, usually offset from its host by pauses on the right boundary (Dehé \& Kavalova 2006). Commas should not be interpreted as necessarily indicating a prosodic break: often the break between what and the preceding element is small or non-existent. The complement is typically - but not always - concluded by a rising, question-like tune (e.g., L- H\%). The examples below show pitch tracks obtained from Praat (Boersma \& Weenink 2009) which were then annotated according to the Tones and Breaks Indices annotation system (Beckman \& Pierrehumbert 1986). All pitch annotations are approximate.

Here we are on the, what, twenty-third floor ${ }^{2}$

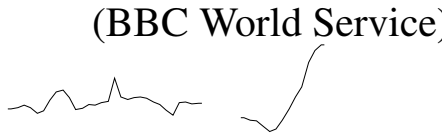

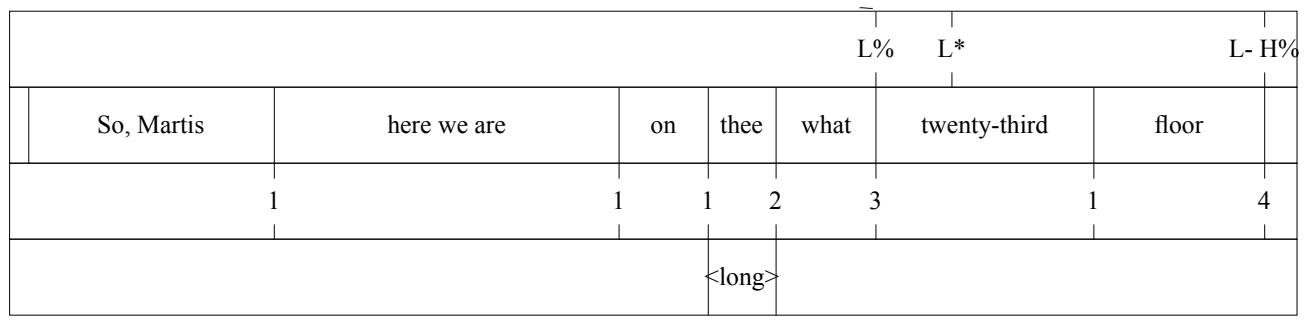

2 Thanks to Radek Šimík for the link to this recording:

http://downloads.bbc.co.uk/podcasts/worldservice/docarchive/docarchive_20090505-1449a.mp3 
Interjective what

(9) I mean, um, you're, what, thirty-seven now? ${ }^{3}$

(NPR's Fresh Air)
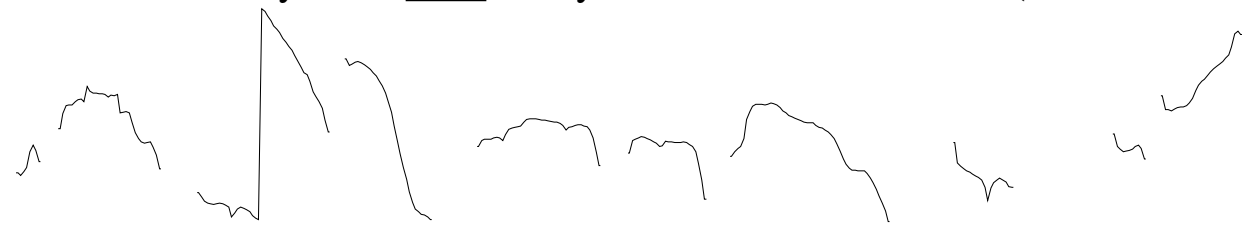

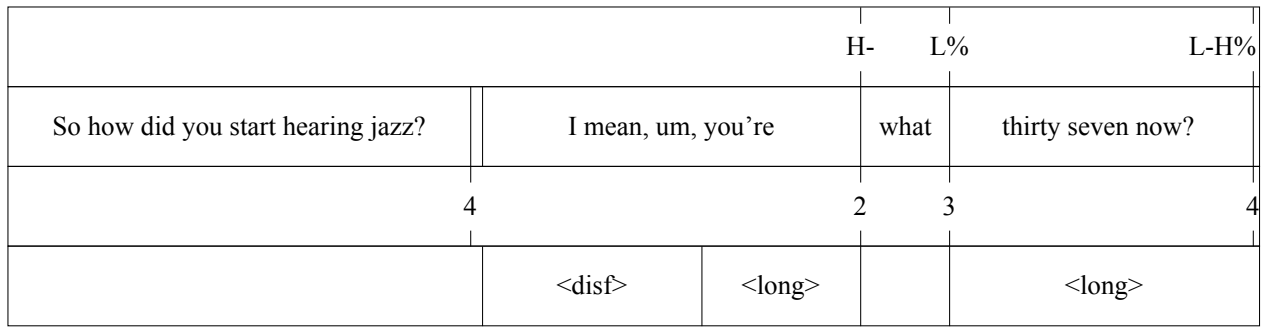

Finally, not all examples conclude with a question-like rising tune (10).

(10) They sold, what, 7.5 million iPads in the first six months that it was on the market. $^{4}$

(NPR's All Tech Considered)

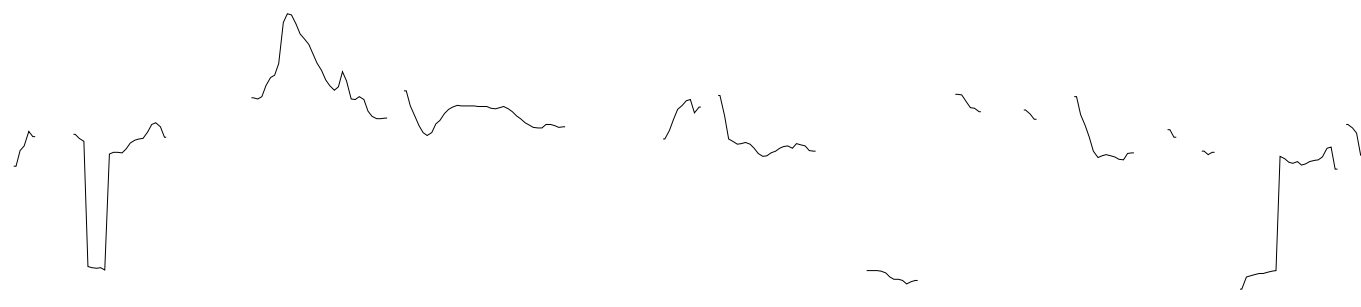

\begin{tabular}{|c|c|c|c|c|c|}
\hline \multicolumn{2}{|c|}{ 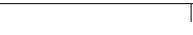 } & 1 & & & $T$ \\
\hline \multicolumn{2}{|c|}{$\mathrm{L} \%$} & $\mathrm{H}^{*}$ & & & $\mathrm{~L} \%$ \\
\hline & - & $\perp$ & & & $\perp$ \\
\hline They sold & what & seven and half million & & iPads in the first six months that & it was on the market \\
\hline & 3 & & & & \\
\hline & $\perp$ & & & & \\
\hline & & & $<$ pause $>$ & & $<$ rapid $>$ \\
\hline
\end{tabular}

The presence of a final fall or rise is most likely related to how the Speaker intends the utterance to be interpreted in discourse: my impression is that when the utterance lacks a final rise, the utterance has a greater chance of being interpreted as a bestguess or approximation, rather than in its interrogative capacity.

3 http://www.npr.org/templates/story/story.php?storyId=101644613

4 http://www.npr.org/templates/transcript/transcript.php?storyId=132631042 
To summarize the main descriptive properties of what so far: syntactically, what is relatively free with respect to its complement, which may be numerical or not. Prosodically, it is produced with a low or low-fall boundary tone, and its complement often displays a rise. These descriptive properties are consistent with several intuitive analyses. I outline three below: what as a $w h$-in-situ question, what as a type of rising declarative, and what as a hesitation marker signaling that the Speaker's epistemic state should be presumed to be weakened regarding the issue. After reviewing the evidence, I propose that what exemplifies distinct weak assertion (approximations or best guesses) and querying functions, but is not syntactically a question.

\section{Analyses}

\subsection{Attempt 1: Wh-in-situ}

The first analysis to consider is one in which an utterance with what is decomposed into a wh-in-situ question, followed by a best-guess fragment answer. In addition to being simple and intuitive, this analysis would reduce the semantics to two independently-needed constituents. Despite its appeal, however, the analysis runs into several empirical problems.

First of all, English wh-in-situ questions are usually licensed in the presence of another wh-element (e.g., Cheng 2009). However, intrasentential what is markedly odd with another $w h$-element: compare (11a) with (11b). Treating what as a $w h$ situ-question would then require departing from the normal syntactic analysis of wh-in-situ questions in English in mysterious and non-trivial ways.

(11) a. You said John drank, what, two beers?

b. ?? Who said John drank, what, two beers?

Second, we would expect that we should be able to rephrase utterances with what as a corresponding canonical question in the general case. Yet, the wh-in-situ question (12b) is not equivalent to the question counterpart (12a) with what, but rather to that of (12c) with how long. This lack of correspondence is simply not predicted under a $w h$-in-situ account.

a. You're been here for, what, 2 years?

b. \# What have you been here for? (2 years?)

c. How long have you been here? (2 years?)

The third issue is that while $w h$-in-situ questions are permitted without a bestguess answer, the what-marker seems to strongly prefer a complement. To illustrate, imagine that you are at a noisy bar. You might utter (13) with rising intonation on 
Interjective what

what as is typical for echo questions..$^{5}$ In this case, the best-guess answer is entirely optional (13a). Yet, with the required low or low fall prosody, as discussed in $§ 2.2$, the complement is not optional (13b).

(13) At a noisy bar:

a. [what uttered with rising intonation:] You want what? (2 beers?)

b. [what uttered with falling intonation:] You want, what, \#(2 beers?)

Furthermore, genuine $w h$-in-situ questions and utterances with what support very different discourse contexts. For example, the $w h$-in-situ echo question above addresses a previous utterance; that is, the Speaker conveys uncertainty about what was said, not necessarily about the accuracy of the statement. In contrast, utterances with what need not address previous utterances and are perfectly acceptable even without discourse contexts - e.g., (16c) in the following section could be produced without any overt context altogether. The prosodic realization on what makes all the difference. 6

In short, numerous counterexamples speak against treating what as a wh-in-situ question. Nevertheless, I'll propose that what is equivalent to a question semantically, introducing a question-like issue into the context, modeled here as a set of propositions, cf. a Hamblin denotation for questions. But, first, we continue onto attempt 2: rising declaratives.

\subsection{Attempt 2: Rising declarative}

Given that utterances with what often appear with a sentence or clause final rise with declarative syntax, it would be natural to align them with rising declaratives (Bartels 1997; Gunlogson 2001, 2008). On Gunlogson's (2008) account, rising declaratives express Speaker commitments for which the Speaker is not a source:

(14) An agent $\alpha$ is a source for a proposition $\phi$ in a discourse $\mathrm{d}$ iff:

a. $\alpha$ is committed to $\phi$; and

b. According to the discourse context, $\alpha$ 's commitment to $\phi$ does not depend on another agent's testimony that $\phi$ in $\mathrm{d}$.

(Gunlogson 2008: 113)

5 In Bolinger's (1957) terminology, the cases below may be more accurately described as reclamatory questions; see Noh (1998) for commentary.

6 Another type of example to compare is that of leading questions, in which the Speaker knows the answer, but expects the Addressee to provide it.

(1) [Teacher, somewhat condescendingly:] Now, students, four plus four is what?

In such cases, it appears that what above is realized with a different sort of prosody: a rise-fall(-rise) on what, displaying mock or rhetorical uncertainty in the sense of Ward \& Hirschberg (1985: §4.3). 
In (15), for example, Speaker A is clearly the source for the commitment regarding whether a leopard is occupying the living room. Speaker B might use a rising declarative to indicate, among other things, that his commitment to the proposition expressed is dependent on $\mathrm{A}$, and requires further ratification before accepting it as true (15b). In contrast, both the polar question and the what-marked counterpart seem pragmatically odd - it is as if Speaker B has completely ignored Speaker A's previous utterance.

(15) A: There's a leopard in the living room.

B's response:

a. \# Is there a leopard in the living room?

(Polar question)

b. There's a leopard in the living room?

(Rising declarative)

c. \# There's, what, a leopard in the living room?

(what-marker)

Note that utterances like (15c) are also perfectly felicitous in contexts where rising declaratives are not:

(16) A: I know what this is (smugly holding up fruit).

B's response:

a. Is that a persimmon?

(Polar question)

b. \# That's a persimmon?

(Rising declarative)

c. That's, what, a persimmon?

(what-marker)

Here, A has not publicly identified the fruit, and thus cannot be taken as a source for the proposition that the fruit is a persimmon. The rising declarative is illicit in this context; it would be licensed if the Speaker were to make a dependent commitment which the Addressee is in a position to confirm. In contrast, both the polar question and the what-marker are permitted.

Like rising declaratives, what is often used in cases of ratification, in which the Speaker seeks participation from his interlocutors. Yet, there are numerous cases in which the Speaker seems happy enough to let the issue go unresolved and it seems that no response is required. These uses can be characterized as weakly assertive in nature, in that they provide an approximately correct range or best guess to which the Speaker is not strongly committed. Such uses constitute the primary source of evidence for treating what as a hesitation marker conveying a weakened epistemic state for the Speaker's public beliefs.

\subsection{Attempt 3: Hesitation marker}

In weak assertion cases, the issue raised by what does not address the main point of the discourse; instead, the complement of what provides an approximately correct 
Interjective what

value or best guess, which may go unaddressed (unless the estimate is egregiously wrong). In the following example, the important issue at hand is not how much time has elapsed; instead, what estimates the time span.

(17) [Message left on answering machine:

Hello, it's Caroline Todd again. It's now 7:09 AM, so that's, what, 8 and a half hours since you came to on your way home from the Pink Lagoon.

(Green Room: Season 1)

Similarly, in (18) the central issue of the statement is not exactly how many disenfranchised Americans are vying for marriage equality; again, the what-marker approximates the percentage, which is, apparently, good enough for the purposes of the conversation.

(18) We've got, what, two or three percent of the population - a tiny number of Americans - who are sincerely saying, 'Let us into this institution: this means everything to us.'

(NPR on marriage equality)

If what may at times estimate, rather than query, a particular value, then we would expect that the issue raised by what sometimes goes unaddressed in discourse. Example (19), from an interview with former Vice President Dick Cheney, provides one such case. ${ }^{7}$

(19) CheneY: I like - Governor Palin. I've met her. I know her. She's [an] attractive candidate. But based on her background, she'd only been governor for, what, two years. I don't think she passed that test.

INTERVIEWER: Of being ready ...

Cheney: Of being ready to take over. $\quad$ (ABC Interview, July 30, 2012)

The interviewer is clearly concerned with continuing the central topic - whether Governor Sarah Palin was an appropriate choice as a running mate - and the use of what indicates that Cheney is unsure or unwilling to commit to the precise length of Palin's term as governor.

Yet another example of a weak assertion use may be seen in (10), shown here with more discourse context, in which two NPR reporters are discussing Apple's regular absence from the Consumer Electronic Show, and the growing popularity of tablet computers.

7 http://abcnews.go.com/blogs/politics/2012/07/transcript-dick-cheneys-first-interview-after-hearttransplant/ 
(20) BLOCK: Laura, let's talk about somebody who will not be at CES this year — that's Apple. They don't go to tradeshows. They do their own thing. But we're all keeping in mind the huge success of the Apple iPad. They sold, what, 7.5 million iPads in the first six months that it was on the market. That's just before the holiday shopping season. So, what kind of competition do you think Apple will be getting for its iPad coming out of CES?

SYDELL: Quite a lot. What Apple proved is that there's a real category for this. A lot of people are really interested in it. So you're going to see tons of tablets.

Again, the issue raised by the utterance with what is not addressed, as doing so would not necessarily further the discourse. As before, the estimate is adequate for the conversation.

These considerations lead us to a general characterization regarding the conventional meaning contributed by what.

(21) Conventional meaning of what. Use of what signals that the Speaker presumes to be in a weakened epistemic state with respect to a value denoted in the complement.

This proposed meaning puts what on par with interjective fillers, like $u h$, um, and elongated thee, (Clark 2004; Fox Tree 2010), which also relate the epistemic state of the Speaker to other discourse participants (Clark \& Fox Tree 2002).

In the remaining sections, I develop a compositional semantics in line with (21). The approach is compatible with both discourse uses of what, in that use of what may pragmatically invite responses to the issue raised, provided that it is pertinent to the immediate topic of discourse.

\section{A formal semantics for what}

Developing a compositional analysis for the what-marker will proceed in two steps. First, we will use tools from Alternative Semantics to produce a set of propositions constituting a partial answer to an issue raised by utterance with what. Such an approach parallels pragmatic halos, in which an utterance denotes not a single proposition, but rather a contextually determined range (Lasersohn 1999; Siegel 2002). Second, we'll sketch how the relation to the discourse topic determines whether the Addressee is expected to further resolve that issue (question use) or leave it unresolved (weak assertion use).

Following Dehé \& Kavalova (2006), I will assume that some element in the complement of what is F(ocus)-marked at the syntactic level (Jackendoff 1972). 
Interjective what

Although F-marking is typically signaled through realization of prosodic focus, it may be syntactically determined as well, as in standard analyses of cleft constructions (e.g., Jackendoff 1972; Atlas \& Levinson 1981). ${ }^{8}$

In Alternative Semantics, each F-marked constituent, e.g., [two $]_{\mathrm{F} 1}$, is translated into a unique designated variable $\mathbf{V}_{\mathbf{1}}$, forming the $p s$-skeleton of the sentence (Rooth 1985; also Jackendoff 1972), The introduction of designated variables is met by the addition of distinguished variable assignments, which assign denotations only for variables of type $\mathbf{V}_{\mathbf{i}, \tau}$ for index $i$ and type $\tau$. Thus, all expressions are interpreted with respect to both ordinary, $g$, and designated variable, $h$, assignments.

Two variable assignments:

(Kratzer 1991)

a. Interpret an ordinary variable $v$ of type $\tau$ : $\left[\left[v_{\tau}\right]\right]^{g, h}=g\left(v_{\tau}\right)$

b. Interpret a designated variable $\mathbf{V}_{\mathbf{i}}$ of type $\tau$ : $\left[\left[\mathbf{V}_{\mathbf{i}, \tau}\right]^{g, h}: h\left(\mathbf{V}_{\mathbf{i}, \tau}\right)\right.$

Accordingly, each expression $\alpha$ is assigned two denotations, one for each variable assignment. The first denotation is delivered by $g$ and corresponds to the usual, ordinary intention. The second denotation is delivered by interpreting designated variables $\mathbf{V}$ with respect to appropriate contextually available distinguished assignment functions $h$. The result is called the $p$-set, a set of alternatives for which functions $h(\mathbf{V})$ are defined (Kratzer 1991).

(23) The p-set for some well-formed expression $\alpha$, with denotations from domain $D_{\tau}$, for an ordinary variable assignment $g$ : $\left[[\alpha]^{g}=\left\{a \in D_{\tau}: \exists h\left[h\right.\right.\right.$ is a distinguished assignment and $\left.a=\left[[\alpha]^{g, h}\right]\right\}$

For illustration, (24) shows all the relevant levels of analysis: a focused constituent indicates F-marking (24a), which is translated into a designated variable within the ps-skeleton (24b). The p-set (24c) consists of the propositions that result from evaluating the ps-skeleton at all available designated variable assignments $h$.

8 An anonymous SALT reviewer observed that the complement does not seem to bear focal prominence, which would undermine the argument for focus marking. While this is certainly true, the focus on the complement might be obscured by the what element itself. Some evidence for this position comes from cases in which what is separated from the term being approximated, as in (5) above. To the extent that such examples are acceptable, (b) and (c) would likely display increased focal prominence:

$$
\begin{aligned}
& \text { a. You've already acted in, what, two plays this year? } \\
& \text { b. ? You've already acted, what, in TWO plays this year? } \\
& \text { c. ? You've already, what, acted in TWO plays this year? }
\end{aligned}
$$

(DP complement)

(PP complement)

(VP complement)

Nevertheless, similar effects may be obtained if we assume that the F-marking in the case of what is achieved via syntactic means alone. 
(24) You've been here TWO years.

a. F-marking: you've been here [two $]_{F 1}$ years

b. Ps-skeleton: you've been here $\mathbf{V}_{\mathbf{1}}$ years

c. P-set: $\left\{p: \exists h\left[h\right.\right.$ is a distinguished assignment and $\left.\left.p=[[(24 \mathrm{~b})]]^{\mathrm{g}, \mathrm{h}}\right]\right\}$

$$
=\left\{\begin{array}{c}
\text { You've been here } 0 \text { years } \\
\text { You've been here } 1 \text { year } \\
\text { You've been here 2 years } \\
\text { You've been here } 3 \text { years } \\
\text { You've been here } 4 \text { years } \\
\text { You've been here } 5 \text { years } \\
\vdots
\end{array}\right\}
$$

When ranging over propositions, the p-set is semantically equivalent to the set of possible answers under a Hamblin-style approach to questions (see Hamblin 1973, as well as Kratzer \& Shimoyama 2002, among many others).

I propose to treat the contribution of what as asserting a restriction on the p-set equivalent to an approximation of answers that cluster around the value provided by the complement. We can visualize the effect in terms of (a) removing propositions not clustered around the asserted value - here, 2 years, and (b) entering all remaining values, as a set, into the discourse. The resulting utterance then resembles a question, albeit with many possibilities already limited to a contextually specified domain. If correct, the denotation of an utterance with what is therefore a subset of the p-set of its prejacent.

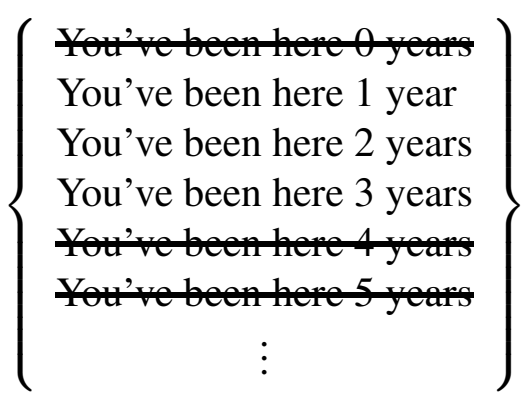

Furthermore, I propose that what signals a sentence operator $\operatorname{AROUND}_{C}$ which takes the ps-skeleton of a proposition and returns a set of propositions obtained by evaluating the ps-skeleton at distinguished assignment functions $h$ from a set of functions $C$. In order to restrict those distinguished assignment functions $h$ in the 
Interjective what

appropriate way, we will need to introduce the following two technical notions: a slack interval and an assignment cluster.

Much like a pragmatic halo, ${ }^{9}$ the slack interval $\mathbb{I}_{i}^{S[\alpha]}$ consists of a set of values centered around the denotation of an expression $\alpha$ from a partially ordered set (poset) $S[\alpha]$ within range $i$ of the denotation of $\alpha,[[\alpha]] .{ }^{10}$ I'll use the notation $c_{n}^{S[\alpha]}$ to refer to an element in the poset determined by $S[\alpha]$ at order $n$. For example, if $c_{n}^{S[\alpha]}=2$, then $c_{n+1}^{S[\alpha]}=3$.

(26) Slack interval. For some well-formed expression $\alpha$, let $\mathbb{I}_{i}^{S[\alpha]}$ be the interval consisting of values from a contextually determined poset $S$ centering around the denotation of $\left[[\alpha]: c_{n}^{S[\alpha]}\right.$ within $\pm i$ on $S$ :

$$
\mathbb{I}_{i}^{S[\alpha]}=\left\{x: c_{n-i}^{S[\alpha]} \leq x \leq c_{n+i}^{S[\alpha]}\right\}
$$

In essence, the slack interval delivers a set of alternative values in $S[\alpha]$ centering around the denotation of $\alpha$ up to index $i$. Next, we define an assignment cluster $C$, which is simply the maximal set of distinguished assignment functions defined for $\mathbf{V}$ which deliver values within $\mathbb{I}_{i}^{S[\alpha]}$ for $\mathbf{V}$.

(27) Assignment cluster. Let $C$ be the set of all assignment functions $h$ for designated variables $\mathbf{V}$, such that for any $h \in C: h(\mathbf{V}) \in \mathbb{I}_{i}^{S[\alpha]}$.

The assignment cluster allows us to now define $\operatorname{AROUND}_{C}$ : an operator signalled by what and that ranges over ps-skeletons and returns a set of propositions.

(28) Propositional operator. Let $p^{\prime}$ be the ps-skeleton of some proposition $p$ : $\operatorname{AROUND}_{C}\left(p^{\prime}\right)=\left\{q: \exists h\left[q=\left[\left[p^{\prime}\right]\right]^{g, h \in C}\right]\right\}$

When applied to a ps-skeleton, AROUND $_{C}$ delivers the set of propositions obtained from evaluating any $\mathbf{V}$ at any function $h$ within the cluster of designated assignment functions $C{ }^{11}$ I assume that the index $i$ and scale $S$ decorating the slack interval $\mathbb{I}_{i}^{S[\alpha]}$ are contextually determined. In the example below, let's take $i$ to be 2 and $S$ to be the natural numbers $\mathbb{N}$.

9 Formally, one might dispense with the slack interval in favor of a pragmatic halo for computing a comparable set of denotations. However, I wish to avoid potential complications that may arise by allowing pragmatic halos, as a general mechanism, to operate over alternative denotations, in addition to ordinary ones.

10 A partially ordered set (poset) $\mathrm{P}$ is a set with a partial order - defined, for $x, y, z \in P$ as a binary relation $\leq$ satisfying (i) reflexivity: $x \leq x$, (ii) antisymmetry: if $x \leq y$ and $y \leq x$, then $x=y$, and (iii) transitivity: if $x \leq y$ and $y \leq z$, then $x \leq z$. See Ward \& Hirschberg 1985 or Partee, Ter Meulen \& Wall 1990 for technical discussion.

11 Edgar Onea (p.c.) observed that the operator will deliver an incorrect representation if there are multiple foci in the sentence, and that this problem may be avoided by giving the variables marked 
(29) You've been here, what, two years?

a. F-marked: you've been here $\left[\mathrm{two}_{\mathrm{F}}\right.$ years

b. Ps-skeleton: you've been here $\mathbf{V}_{\mathbf{1}}$ years

c. $\operatorname{AROUND}_{C}[[(29 b)]]^{g, h \in C}$

$$
=\left\{\begin{array}{l}
\text { You've been here } 1 \text { years } \\
\text { You've been here } 2 \text { years } \\
\text { You've been here } 3 \text { years }
\end{array}\right\}
$$

So much for the core of the semantic proposal. Before turning to the effect of what in discourse, I briefly raise a few issues regarding the semantics I advocated above.

First, I have assumed without much discussion that the alternative values are ordered along a scale $S[\alpha]$, defined in terms of a poset. The slack interval was defined so as to pick out a set of alternative values to the denotation of the focused term within the complement. Many, but not all, complements are numerical. Since the scale $S$ is not given explicitly, it must be extracted from context. Assuming that numerical terms, or at least the natural numbers, form a natural scale in any context, numerical terms are well suited to satisfy conditions on what. As expected, terms that do not form scales easily (e.g., straight) appear to be incompatible with what. Insofar as (30) is acceptable, it appears to have a sarcastic interpretation, as opposed to the approximative reading of interest.

(30) \# The rod was, what, straight?

Examples with non-numerical terms are telling - many seem to be coerced into a scale through some kind of contextually salient relation, often one of prototypicality:

(31) [Seeing a book on the lambda calculus.] You're, what, a semanticist?

In the example above, the Speaker has assumed that semanticists are likely to read books on the lambda calculus. Presumably, comparable professions would include mathematicians, computer scientists, and so on. Such cases could also be treated in terms of a best guess. Formally, the element would reduce to a singleton element, which trivially satisfies the poset requirement.

Second, it is doubtful that what has an approximative lexical meaning of its own. Since there are multiple ways to achieve a similar effect without the use of what, it is likely that what does not denote, but merely signals, AROUND ${ }_{C}$. There are several sources of evidence compatible with this claim. For example, pauses and other approximations, such as like or about, seem to give rise to a very similar meaning:

by what a unique type of designated variable. However, as I have found no cases of multiple foci in such cases, and have been unable to construct a natural example, I will not complicate the semantics with additional variable types at this point. 
Interjective what

(32) a. You've been here, what, two years?

b. You've been here 〈pause $\rangle$ two years?

c. You've been here like/about two years?

What's more, other $w h$-words can serve a similar function, although less productively:

(33) a. John moved to Claremont, when, last month?

b. Mary corrected, who, Phil?

In addition, the what-marker co-occurs with other approximative terms, as in (34), disjunctions, as in (35), and even multiple complements, as in (36):

(34) A. How long has he been dead?

(Numbers: Season 2)

B. According to the coroner's report, about 24 hours.

C. That's, what, like two days after the break in at Skylar Wyatt's house?

(35) I mean, face it you can buy pharmaceutical grade cocaine for what, ten or twenty dollars an ounce

(Switchboard)

(36) I'm no expert but, my guess is that a high rise at this location has gotta fetch at least, what, three, four hundred million?

(Numbers: Season 5)

Observing similar cases, Dehé \& Kavalova (2006) argued that what has a procedural meaning alone: it is an element with functional, but not conceptual or representational, meaning (as discussed in the Relevance Theory literature; see in particular Blakemore 2004). Procedural meanings are said to constrain the discourse inferences that can be drawn using representational meanings. The approach above differs from theirs in that what does have a conventional meaning, which signals an operator with an ordinary representational meaning. However, I fully acknowledge the empirical observation that what places constraints on the development of discourse. I argue that the approach above grants some insight into the various discourse uses it supports. This issue is taken up in the next section.

\section{Using what in discourse}

As seen above, there are at least two major kinds of uses for what in discourse: (i) a querying function and (ii) an approximative or best-guess use, which I have combined as the weak assertion function. Given the hypothesized meaning in (21), the strategy is now to show that both major functions are compatible with the core semantics of AROUND $C$. Since what, by hypothesis, expresses Speaker uncertainty, it should not, by itself, signal that Addressee needs to respond. Rather, the Speaker 
may use it to issue an indirect question when the approximated complement pertains directly to the discourse topic.

I adopt Roberts's (1996) statement that discourse is “organized around a series of conversational goals and the plans, or strategies, which conversational participants develop to achieve them" and her notion of a Question under Discussion (QuD), the immediate topic of discussion (see also Von Stutterheim \& Klein 1989, Ginzburg 1996, and Büring 2003, as well as Farkas \& Bruce 2010). The two uses of what then correlate with two different discourse strategies. Assuming that participants all have access to the $\mathrm{QuD}$, the intended use can be (at least partially) determined by a relation between the active $\mathrm{QuD}$ and the epistemic states of the discourse participants. The two major uses of what are illustrated in broadly Gricean terms (Grice 1975).

I. Query: If the issue raised by the use of what relates directly to the $\mathrm{QuD}$, a cooperative Addressee will attempt to resolve it. A cooperative Speaker knows this and so will use what as a query when he wishes to indicate that the issue needs resolving.

II. Weak assertion: If the issue raised by what does not directly relate to the QuD, a cooperative Addressee need not address it, especially if doing so would violate Relevance. A cooperative Speaker should appreciate the Addressee's position and reserve using what as a weak assertion in such contexts to only semantically approximate the complement or to provide a best-guess.

These two discourse strategies yield a straightforward prediction: when the Speaker has privileged epistemic access to the information conveyed by the complement, the use of what should be interpreted as a weak assertion, and, as such, the issue raised by what should be less likely to elicit a direct response from the Addressee.

In order to test this prediction, examples from the Switchboard fragment were coded according to whether the example elicited a response or not. Although the sample is small, the results are suggestive. In the following examples, the issue raised by what pertains to the Speaker's personal history. As predicted, these cases do not elicit a response from the Addressee, and are not part of the QuD.

(38) 164 utt3: I moved down here from Chicago, what, twenty-three years ago 165 utt 1: \{f oh, $\}$ uh-huh

166 utt 1: $-[$ and, + ] to Lewisville -

(39) 154 utt1: - \{c but, $\}$ when we first moved to Coppell, \{a it's what, six years ago, \} we didn't even have a grocery store

155 utt $1:\{$ f oh, $\}$ wow,

156 utt 1: $-\{\mathrm{c}$ and $\}$ now we have four $<$ laughter $>$ 
Interjective what

In contrast, the next example occurs at the beginning of the dialogue, when the participants are given topics to discuss. Apparently, one of the participants didn't hear or understand what the topic was and asks the other for clarification. Here, the Addressee has access to the information conveyed in the complement, and the issue relates straightforwardly to the QuD. As predicted, what appears to have been interpreted in its querying capacity:

1 utt2: I missed a part of it

1 utt3: we're to talk about what, lawns and gardens

2 utt1: lawn and garden work and what you enjoy and what kind of work you do

This final case contains two instances of what. It differs from the others in that even though resolving the issue seems relevant to the current $\mathrm{QuD}$, it can't be resolved by either one of the discourse participants.

(41) 34 utt2: $\{\mathrm{c}$ and, $\}$ \{d you know, $\}$ we're like, $\{\mathrm{d}$ what, $\}$ one of two backwards countries in the world, as far as,

35 utt1: yeah,

35 utt2: I read that, what, Uganda and,

36 utt1: something

36 utt2: I don't remember what the other one is

The above examples are consistent with the claim that what expresses Speaker uncertainty and that for it to be interpreted as an indirect question, it ought to relate to the immediate QuD. Real examples like these present difficulties for analysis, while indicating the empirical richness of what that is yet to be explored.

The space remaining is dedicated to a few brief remarks regarding how what might dynamically update the discourse. I've proposed that what raises a questionlike issue to which it provides a partial answer. In other words, utterances with what propose a partial update of the common ground, in many cases inviting collaboration between discourse participants to jointly ground information within the discourse (Clark \& Wilkes-Gibbs 1986; Clark \& Schaefer 1989). In the vocabulary of Inquisitive Semantics (e.g., Groenendijk \& Roelofsen 2009), what is both inquisitive, in that it raises possibilies, and informative, in that it proposes to exclude possibilities. Combined with an agent-oriented delineation of discourse context, dynamic approaches of discourse update offer a promising avenue for treating the nuances that govern the use of what. However, I must leave a more systematic investigation of this topic for another occasion. 


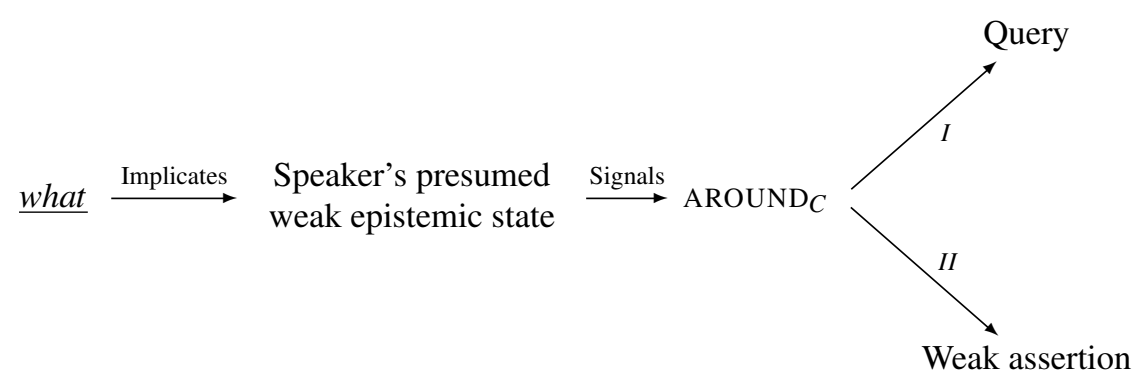

Figure 1 Account of interjective what.

\section{Concluding remarks}

In this paper, I introduced the central descriptive properties for utterances containing intrasentential what. I argued that what is a syntactically free hesitation marker that implicates that the Speaker's presumed or public epistemic state is weak with respect to the information conveyed in the complement. I developed a compositional semantics for what in which what pragmatically signals a focus-sensitive operator which, in turn, produces a question-like set of alternative answers. The proposed semantics was then shown to be compatible with both a querying and a weak assertion function of what. The overall account is depicted in Figure 1.

I hope to have illustrated how what might be treated within a compositional semantics when complemented with notions inherited from discourse management. Yet, much remains to be done. Interjective what intuitively shares several properties exhibited by discourse particles in many of the world's languages, and would doubtless benefit from a more direct comparison (for example, the weak assertion function is in certain respects similar to the discourse particle wohl in German). Hopefully, the remarks here will have sufficed to show that there is much to be said regarding the semantics and pragmatics of the commonly used yet largely ignored particle what, adding to the myriad of ways in which speakers manage to convey information despite their own imperfect or partial knowledge states.

\section{References}

Atlas, Jay David \& Stephen C. Levinson. 1981. It-clefts, informativeness, and logical form: Radical pragmatics (revised standard version). In Peter Cole (ed.), Radical Pragmatics, 1-61. Academic Press. 
Interjective what

Bartels, Christine. 1997. Towards a compositional interpretation of English statement and question intonation: University of Massachusetts, Amherst dissertation.

Beckman, Mary E. \& Janet B. Pierrehumbert. 1986. Intonational structure in Japanese and English. Phonology Yearbook 3. 15-70.

Bird, Steven, Ewan Klein \& Edward Loper. 2009. Natural Language Processing with Python. O'Reilly Press.

Blakemore, Diane. 2004. Discourse markers. In Laurence R. Horn \& Gregory Ward (eds.), The Handbook of Pragmatics, chap. 10, 221-240. Malden, MA: Blackwell Publishing.

Boersma, Paul \& David Weenink. 2009. Praat: doing phonetics by computer. Http://www.praat.org/.

Bolinger, Dwight. 1957. Interrogative Structures of American English: The Direct Question. University of Alabama, Alabama: University of Alabama Press.

Büring, Daniel. 2003. On d-trees, beans, and b-accents. Linguistics and Philosophy 26(5). 511-545.

Cheng, Lisa Lai-Shen. 2009. Wh-in-situ, from the 1980s to now. Language and Linguistics Compass 3(3). 767-791.

Clark, Herbert H. 2004. Pragmatics of language performance. In Laurence R. Horn \& Gregory Ward (eds.), Handbook of Pragmatics, chap. 16, 365-382. Oxford: Blackwell.

Clark, Herbert H. \& Jean E. Fox Tree. 2002. Using $u h$ and $u m$ in spontaneous speaking. Cognition 84. 73-111.

Clark, Herbert H \& Edward F Schaefer. 1989. Contributing to discourse. Cognitive Science 13(2). 259-294.

Clark, Herbert H \& Deanna Wilkes-Gibbs. 1986. Referring as a collaborative process. Cognition 22(1). 1-39.

Dehé, Nicole \& Yordanka Kavalova. 2006. The syntax, pragmatics, and prosody of parenthetical what. English Language and Linguistics 10(2). 289-320.

Eggers, Dave. 2006. What is the What. New York: Vintage Books.

Farkas, Donka F. \& Kim B. Bruce. 2010. On reacting to assertions and polar questions. Journal of Semantics 27(1). 81-118.

Fox Tree, Jean E. 2010. Discourse markers across speakers and settings. Language and Linguistics Compass 4(5). 269-281.

Ginzburg, Jonathan. 1996. Dynamics and the semantics of dialogue. In Jerry Seligman \& Dag Westerstøahl (eds.), Logic, Language, and Computation, vol. 1, CSLI Publications.

Godfrey, John J., Edward C. Holliman \& Jane McDaniel. 1992. Switchboard: Telephone speech corpus for research and development. In Acoustics, Speech, and Signal Processing, ICASSP-92, vol. 1, 517-520.

Grice, Paul H. 1975. Logic and conversation. In Peter Cole \& Jerry Morgan (eds.), 
Syntax and Semantics, vol. 3: Speech Acts, 43-58. New York: Academic Press. Groenendijk, Jeroen \& Floris Roelofsen. 2009. Inquisitive semantics and pragmatics. Presented at the Workshop on Language, Communication and Rational Agency, Stanford University.

Gunlogson, Christine. 2001. True to form: Rising and falling declaratives as questions in English. Santa Cruz: University of California, Santa Cruz dissertation.

Gunlogson, Christine. 2008. A question of commitment. Belgian Journal of Linguistics 22(1). 101-136.

Hamblin, Charles L. 1973. Questions in Montague English. Foundations of Language 10. 41-53.

Hammett, Dashiell. 1929. Red Harvest. New York, NY: Vintage Crime/Black Lizard.

Jackendoff, Ray. 1972. Semantic Interpretation in Generative Grammar. Cambridge, MA: MIT Press.

Kratzer, Angelika. 1991. The representation of focus. In A. von Stechow \& D. Wunderlich (eds.), Semantik: Ein internationales Handbuch der zeitgenoessischen Forschung, 805-825. Berlin: de Gruyter.

Kratzer, Angelika \& Junko Shimoyama. 2002. Indeterminate pronouns: The view from Japanese. In Yukio Otsu (ed.), The Third Tokyo Conference on Psycholinguistics, 1-25. Tokyo.

Lasersohn, Peter. 1999. Pragmatic halos. Language 75(3). 522-551.

McCready, Eric. 2008. What man does. Linguistics and Philosophy 31(6). 671-724.

Noh, Eun-Ju. 1998. Echo questions: Metarepresentation and pragmatic enrichment. Linguistics and Philosophy 21(6). 603-628.

Partee, Barbara Hall, Alice G. B. Ter Meulen \& Robert E. Wall. 1990. Mathematical Methods in Linguistics. Dordrecht, The Netherlands: Kluwer Academic Publishers.

Roberts, Craige. 1996. Information structure: Towards an integrated formal theory of pragmatics. In Jae Hak Yoon \& Andreas Kathol (eds.), OSUWPL Volume 49: Papers in Semantics, The Ohio State University.

Rooth, Mats. 1985. Association with Focus. Amherst, MA: University of Massachusetts, Amherst dissertation.

Siegel, Muffy. 2002. Like: Discourse particle and semantics. Journal of Semantics 19(1). 35-71.

Von Stutterheim, Christiane \& Wolfgang Klein. 1989. Referential movement in descriptive and narrative discourse. In Rainer Dietrich \& Carl F. Graumann (eds.), Language Processing in Social Context, 39-76. Elsevier Science Publishers.

Ward, Gregory \& Julia Hirschberg. 1985. Implicating uncertainty: The pragmatics of fall-rise intonation. Language 61(4). 747-776.

Zimmermann, Malte. 2011. Discourse particles. In Paul Portner, Claudia Maienborn 
Interjective what

\& Klaus von Heusinger (eds.), Handbücher zur Sprach- und Kommunikationswissenschaft HSK 33.2, 2011-2038. Berlin: Mouton de Gruyter.

Jesse A. Harris

Linguistics \& Cognitive Science

185 East Sixth Street

Pomona College

Claremont, CA 91711

Jesse.Harris@pomona.edu 